\title{
Mathematical Modeling of Heat Transfer of Liquefied Natural Gas Engines
}

\author{
Milica NIKODIJEVIC, Radovan PETROVIC, Sergey V. BOCHKAREV, Nenad TODIC, Ivica STANKOVIC
}

\begin{abstract}
The article presents a mathematical model for pressure growth in the line supplying the engine KAMAZ with cryogenic fuel under specific insulation conditions. By using the heat balance equation the model in a simple linear form is obtained. This makes the model suitable for use in solving practical tasks related to the design of a liquefied natural gas engine fuel system. According to the above-mentioned method, the geometric parameters of the section of the main elements are determined under different external conditions and the boundary parameters of the gas fuel (maximum and minimum values of pressure, temperature, and flow). These data are necessary to determine the consumption, hydraulic and project features of the project. Fuel pipes are optimized (for hydraulic resistance, pressure and flow impulses, structural strength) to improve the accuracy of fuel dosing. The adequacy of the model was tested on a special modified test stand.
\end{abstract}

Keywords: calculation; engine; experiment; frequency of pressure measurement; heat; liquefied natural gas; pipeline; pressure

\section{INTRODUCTION}

Natural gas is an alternative fuel for use in engines of different types of transport [1]. Compressed natural gas $\mathrm{CNG}$ is known, methane compression is obtained up to 25 $\mathrm{MPa}$ [4] and [5]. However, a number of objective shortcomings in the use of CNG disable the propagation of the gas balloon car. This is a small set-back of the car's strength due to the $3-4$ times smaller CPG density compared to gasoline, which is a large proportion of the mass of gas balloons compared to the mass in it. [5] and [6].

Effective increasing of the gas density is achieved by lubricating it, increasing the density by 640 times [8] and [9]. Liquid natural gas LNG is a cryogenic product obtained from natural gas with the content of methane through its purification and lubrication [3]. The amount of methane in natural gas varies depending on the deposit from 70 to $99 \%$. The energy efficiency of LNG is higher than the energy efficiency of gasoline [10]. However, at low temperatures (minus $160^{\circ} \mathrm{C}$ and below), the exchange of heat with the environment leads to increased pressure in balloons and vehicles with fuel injection with gas phase formation. Ignition of fuel system elements can be avoided by uncontrolled pressure increase [11].

The use of modern thermal insulation of the pipeline does not exclude the possibility of redirecting LNG, but only reduces the rate of pressure increase. Security issues which require theoretical and experimental determination at the design level of effective thermal insulation, for reducing the pressure gain, are arising.

Based on the researches outlined in the available literature, the lack of a good mathematical model for liquefied natural gas engines, and in particular the fuel distribution pressure distribution algorithm, is noticed.

The purpose of this paper is to develop an appropriate mathematical model and method of engineering calculations, which predicts an increase in engine fuel system pressure, as well as the development of an automated cryogenic fuel management system.

\section{MATHEMATICAL MODEL}

In accordance with the works of [12-14] it is considered the section of the fuel system pipeline with length $L$, with the inside diameter $d$ and a layer of insulation diameter $D$, Fig. 1. Liquid methane at boiling point $T_{\mathrm{g}}$ is flowing in the direction of the $x$ axis with a mass consumption in second $G$. Through a layer of insulation from the environment with a temperature $T_{\mathrm{e}}$, there is specific heat transfer $q_{\mathrm{L}}(\mathrm{W} / \mathrm{m})$, so that the total power input of heat within the entire length of the pipeline is:

$N=q_{\mathrm{L}} \cdot L$

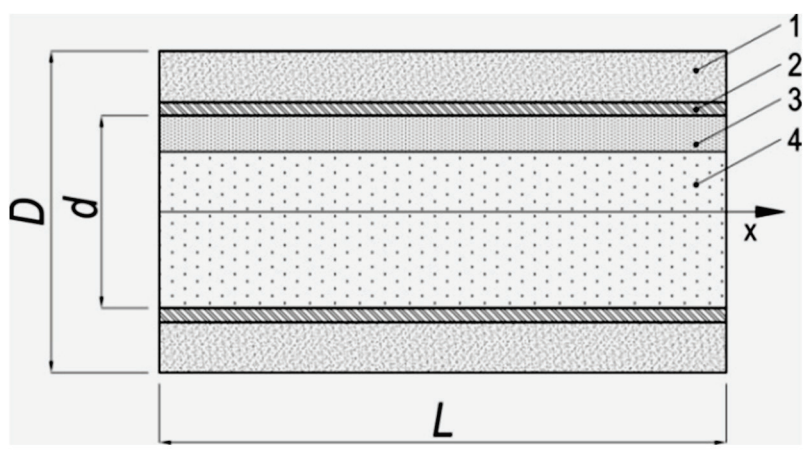

Figure 1 The scheme of the pipeline: 1 - heat insulation, 2 - trumpet, 3 - gas pillow, 4 - LNG

Heat supply through the pipe wall leads to the formation of the gaseous methane with weight $m_{\mathrm{g}}$, in accordance with the equation of heat balance.

$N=K_{\mathrm{L}} \cdot\left(T_{\mathrm{e}}-T_{\mathrm{g}}\right) \cdot L=Q \frac{\mathrm{d} m_{\mathrm{g}}}{\mathrm{d} \tau}$

where: $K_{\mathrm{L}}$ - is coefficient of heat transfer through a cylindrical wall, $\mathrm{W} /(\mathrm{m} \cdot \mathrm{K})$, taking into account the material properties of insulation and pipes [14-16] as well as methane flow regimes and external heat exchange; $Q$ - is the specific heat of evaporation, $\mathrm{J} / \mathrm{kg} ; \tau$ - is the time, $\mathrm{S}$.

Integrating Eq. (2) gives the constant power input of heat line-height weight gaseous methane [3].

$m_{\mathrm{g}}=\frac{N \tau}{Q}+m_{\mathrm{gi}}$

where: $m_{\mathrm{gi}}$ - is the constant of integration here which represents the mass of gaseous methane at the initial point: 
$m_{\mathrm{gi}}=\frac{\mu V p_{\mathrm{i}}}{R T_{\mathrm{g}}}$

where: $\mu$ - is methane molar mass, $V$ - is pipe volume, $p_{\mathrm{i}}$ is atmospheric pressure, $R$ - is universal gas constant and $T_{\mathrm{g}}$ - is gas temperature.

We assume that formed in the pipeline, gaseous methane complies with the ideal gas equation:

$$
p=\frac{m_{\mathrm{g}}}{\mu} \frac{R T_{\mathrm{g}}}{V}
$$

where: $p$ - is pressure; $R$ - is the universal gas constant; $\mu$ is the mass praying methane; $V$ - is the volume of the pipeline.

By substituting Eq. (3) and Eq. (4) in Eq. (5) the distribution of pressure is obtained:

$$
p=p_{\mathrm{i}}+\frac{R T_{\mathrm{g}}}{\mu V} \frac{N}{Q} \tau
$$

The second addend in Eq. (6) represents an overpressure in the pipes:

$$
p_{\mathrm{m}}=\frac{R T_{\mathrm{g}}}{\mu V} \frac{N}{Q} \tau
$$

It is assumed that by forming in the pipeline, gaseous methane coincides with the ideal gas equation. Relationships describe the rising pressure in the closed pipeline due to the flow velocity, depending on the external heat exchange conditions for the liquid density $\rho_{1}$. The heat transfer through the wall of the pipeline leads to the formation of a saturated liquid, the gas density $\rho_{\mathrm{g}}$, the fuel is the two-phase flow of liquid and gas density [2].

$$
\rho_{\mathrm{gl}}=\rho_{1}\left[1-\left(\frac{\rho_{\mathrm{l}}}{\rho_{\mathrm{g}}}-1\right) \frac{q_{\mathrm{L}} L^{2} \pi d^{2}}{4 Q G}\right]
$$

The power of the $N_{\mathrm{gl}}$ required to pump two-phase (gasliquid) flow increases pumping capacity compared to homogeneous liquid flow $N_{1}$ [2]

$$
N_{\mathrm{gl}}=\psi N_{1} \frac{\rho_{\mathrm{l}}}{\rho_{\mathrm{gl}}}
$$

The function $\psi$ depends on the relationship between the force of gravity, surface tension, and inertia, which influences the shape and size of gas bubbles in the amount of liquid gaseous mixtures based on the theory of similarity, shown in the reference [2].

Control of input LNG in the fuel system engine. Increasing the pressure in the engine fuel system depends on its thermal insulation and the characteristics of the consumable materials, which create additional risk of overflow for both vehicle and environment users. Fuel pressure increase rate depends on LNG consumption: when there is low pressure, consumption is faster, and when
LNG supply stops (stopping the engine), the pressure reaches such a value, which can lead to the destruction of gas equipment [23]. In order to avoid an emergency situation, the fuel system must work in automatic mode to prevent the risk of destruction. The automated system must respond adequately to pressure changes with a frequency that depends on the engine mode. The task appears of creating a mathematical model for predicting the pressure measurement frequency with the engine of the automated control system.

Existing technological limitations determine the following ways of stabilizing the pressure: through fuel consumption control or overpressure over a microwave machine. The purpose of the control is to regulate the pressure in the fuel pipe at the valid values at regular intervals. It is ultimately defined as a task to minimize time pressure change or execution of a task.

According to Eq. (5) for the formation of gaseous methane, the gas at the fuel pressure increases from the initial pressure $p_{\mathrm{i}}$ to the linear law:

$p=p_{\mathrm{i}}+\frac{R T_{\mathrm{g}}}{\mu V} \frac{q_{\mathrm{L}} L}{Q} \tau$

where $V$ - is the volume of the fuel line; $q_{\mathrm{L}}$ - is the flow of heat input per unit length of the fuel line (heat flux of specific gravity); $L$ - is the length of the fuel line. In view of the volume of the fuel line $V=\frac{\pi d^{2} L}{4}$ this equation takes the form:

$p=p_{\mathrm{i}}+\frac{4 R T_{\mathrm{g}}}{\mu \pi d^{2}} \frac{q_{\mathrm{L}}}{Q} \tau$

It shows that in order to raise the pressure $p$ from some initial value $p_{\mathrm{i}}$ to the nominal $p_{\text {nom }}$, required exposure time and identified time management $\tau_{\mathrm{k}}$ of fuel line is:

$\tau_{k}=\frac{p_{\text {nom }}-p_{\mathrm{i}}}{4 R T_{\mathrm{g}}} \frac{q_{\mathrm{L}}}{\mu \pi d^{2}}$

For the accuracy of this model, it is necessary to determine the accuracy of the pressure distribution, i.e. Eq. (6), i.e. Eq. (7), which will be done in the next chapter.

\section{EXPERIMENT DESCRIPTION}

In this section, to determine the accuracy of the pressure distribution, i.e. Eq. (6) and Eq. (7), measurements will be performed on the modified stand $[19,20]$.

The modified stand (Fig. 2) [3] includes fuel truck or refills capacity 1 , cryogenic tank 9 , filling limit gauges 12 , pressure 7 , gates 3,16 , electric pneumatic valves 2,15 , pressure gauges 4,14 , valve gear boxes 3 , protective membrane 6 and piping. The filler sensor serves to determine the end of the 12 charge points with the fuel, charging the cryogenic tank. Tube 8 is used for drainage of cryogenic tank vaporized gas. To prevent dangerous pressure increase in the cryogenic reservoir, a production 
line consisting of pressure sensors 7 , valve 5, and membrane 6 is used. Tube 13 is used to drain the liquid gas from the cryogenic tank. The electric pneumatic valves 2 and 15 are installed for remote control of the system [21].

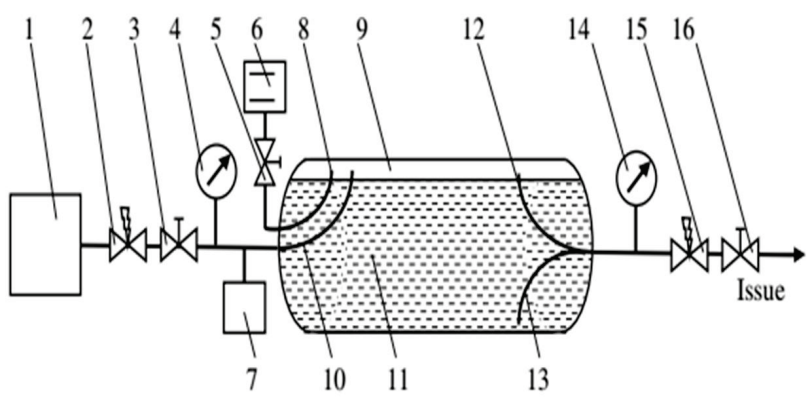

Figure 2 Scheme of modified stand for experiment [3]: 1 - refill capacity; 2, 15 electric pneumatic valves; 3,16 - valves; 4, 14 - pressure gauges; 5 - valve with manual control; 6 - protective membrane; 7 - pressure sensor; 8 - tube for drainage; 9 - cryogenic tank; 10 - snorkel for filling liquefied gas; 11 - liquefied gas; 12 - filling limit sensor; 13 - the tube for discharge of liquefied gas

The cryogenic tank shown in Fig. 3 is made of steel and wrapped in organic plastic. During testing at atmospheric pressure and the ambient temperature of 20 $\pm 5{ }^{\circ} \mathrm{C}$, the cryogenic tank is placed in an aluminum housing.

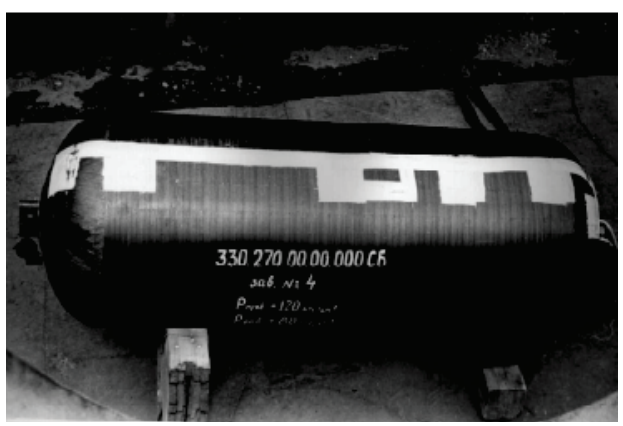

Figure 3 The image of the cryogenic tank with pasted sensors

The test methodology involves the preparation of a measuring system for testing, installation tests, cryogenic vessel leak testing, liquid methane in balance and finally refilling. Measurement information was recorded using the temperature sensor, pressure, and deformation of the microprocessor telemetry station.

\section{RESULT AND DISCUSSION}

The measurement of the overpressure and its determination by analytical use of Eq. (7) is performed for the physical model for which data are given in Tab. 1.

Table 1 Characteristics of liquefied natural gas in the conditions of the experiment

\begin{tabular}{|c|l|c|c|}
\hline No & \multicolumn{1}{|c|}{ Parameter } & $\begin{array}{c}\text { Unit of } \\
\text { measure }\end{array}$ & $\begin{array}{c}\text { The } \\
\text { numerical } \\
\text { value }\end{array}$ \\
\hline 1 & Volume of cryogenic tank $/ V$ & $\mathrm{~m}^{3}$ & 0,26 \\
\hline 2 & Density of gaseous methane $/ \rho_{\mathrm{g}}$ & $\mathrm{kg} / \mathrm{m}^{3}$ & 82,1 \\
\hline 3 & Density of liquid methane $/ \rho_{\mathrm{l}}$ & $\mathrm{kg} / \mathrm{m}^{3}$ & 422 \\
\hline 4 & Enthalpy of vaporization $/ Q$ & $\mathrm{~kJ} / \mathrm{kg}$ & 511 \\
\hline 5 & Boiling point $/ T_{\mathrm{g}}$ & $\mathrm{K}$ & 111,7 \\
\hline 6 & Ambient temperature $/ T_{\mathrm{e}}$ & $\mathrm{K}$ & 293 \\
\hline 7 & The supplied heat flow $/ N$ & $\mathrm{~W}$ & 115 \\
\hline 8 & Mass spraying of methane $/ \mu$ & $\mathrm{kg} / \mathrm{kmol}$ & 0,016 \\
\hline 9 & Universal gas constant $/ R$ & $\mathrm{~J} /(\mathrm{mol} \cdot \mathrm{K})$ & 8,314 \\
\hline
\end{tabular}

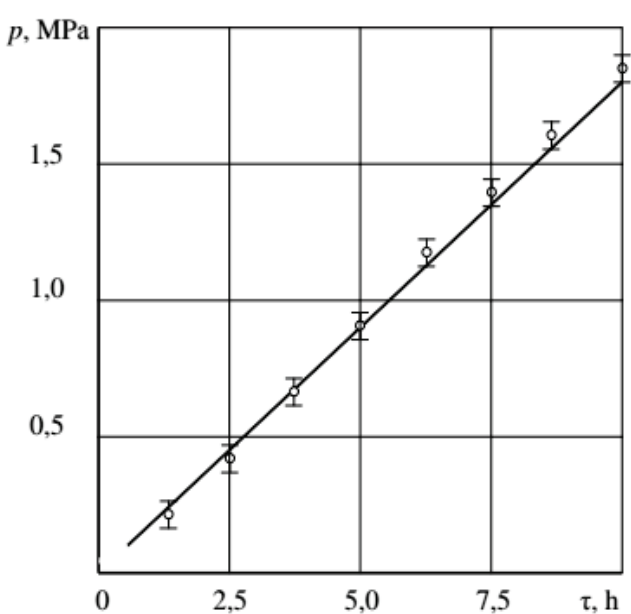

Figure 4 Increased pressure in the tank volume $0,26 \mathrm{~m}^{3}$ with LNG at valid thermal stream $N=115 \mathrm{~W}$. Line - calculation of Eq. (4), point - experiment

Fig. 4 shows the results of an experiment presenting the heat leakage from the surrounding air to thermal insulation of the cryogenic tank [22], the pressure increases from the original $0,1 \mathrm{MPa}$ up to $2 \mathrm{MPa}$ for 10 hours.

The assumption is that constant temperature does not lead to large deviations in the distribution of pressure.

\section{EXAMPLE OF APPLICATION}

For example, we evaluate the fuel delivery control line when the original data is in Tab. 2.

Table 2 The characteristics of the fuel line, adopted by the calculation

\begin{tabular}{|c|l|c|c|}
\hline No & \multicolumn{1}{|c|}{ Parameter } & $\begin{array}{c}\text { Unit of } \\
\text { measure }\end{array}$ & $\begin{array}{c}\text { The numerical } \\
\text { value }\end{array}$ \\
\hline 1 & Inside diameter of the fuel line $/ d$ & $\mathrm{~m}$ & 0,03 \\
\hline 2 & The length of the fuel line $/ L$ & $\mathrm{~m}$ & 1 \\
\hline 3 & The massive second consumption $/ G$ & $\mathrm{~kg} / \mathrm{s}$ & $5,1 \times 10^{-3}$ \\
\hline 4 & Heat flux of specific gravity $/ q_{\mathrm{L}}$, & $\mathrm{W} / \mathrm{m}$ & 2 \\
\hline
\end{tabular}

In Eq. (12) the rate of change of pressure in the fuel line $\frac{p_{\text {nom }}-p_{\mathrm{i}}}{\tau_{\mathrm{k}}}$ will be:

$\frac{4 R T_{\mathrm{g}}}{\mu \pi d^{2}} \frac{q_{\mathrm{L}}}{Q}=3.2 \times 10^{2} \frac{\mathrm{Pa}}{\mathrm{s}}$

When you change the pressure $p_{\text {nom }}-p_{\mathrm{i}}$ more than $10^{4} \mathrm{~Pa}$, the frequency of external governs impacts on the fuel line is:

$\tau_{\mathrm{k}}=\frac{p_{\text {nom }}-p_{\mathrm{i}}}{\frac{4 R T_{\mathrm{g}}}{\mu \pi d^{2}} \frac{q_{\mathrm{L}}}{Q}}=3125 \mathrm{~s}$

Thus, the feed control of LNG is reduced to discrete monitoring of pressure with a frequency reaches $1 / \tau_{\mathrm{k}}$ depending on the mode of operation of the engine.

\section{CONCLUSION}

A new mathematical model and algorithm for determining fuel pressure increase have been proposed. 
Fuel pipelines are optimized to improve metering accuracy.

The results thus obtained are compared with experimental results obtained on a modified base. These results show that this mathematical model and algorithm are recommended for further research and practice.

The proposed mathematical model and algorithm provide an adequate description of the increase in pressure in a fuel cell with heat-insulated liquid natural gas ranging from $0,1 \mathrm{MPa}$ to $2 \mathrm{MPa}$ and can be useful for designing thermal insulation parameters, cryogenic power of fuel under specific insulating conditions, predicting energy management and pressure measurement in the engine management system.

\section{Acknowledgements}

Some of these studies were supported by the Ministry of Education and Science of the Republic of Serbia, grant TR 32036 and Grant TR 35038.

\section{REFERENCES}

[1] Tsaplin, A. I. \& Bochkarev, S. V. (2009). Technique of thermal calculation of a carrier liquid natural gas. International science and technology journal Alternative Fuel Transport, 8(2), 70-73.

[2] Tsaplin, A. I. \& Bochkarev, S. V. (2011). Simulation of heat transfer for liquefied natural gas engine. International science and technology journal Alternative Fuel Transport, 21(3), 66-69.

[3] Tsaplin, A. I. \& Bochkarev, S. V. (2016). Mechanical Behavior of a Metal Composite Vessels under Pressure at Cryogenic Temperatures. Mechanics of Composite Materials, 51(6), 721-730. https://doi.org/10.1007/s11029-016-9542-y

[4] Tsaplin, A. I. \& Bochkarev, S. V. (2011). Evaluation of energy consumption when filing a LNG in an engine. International science and technology journal Alternative Fuel Transport, 24(6), 68-70.

[5] Tsaplin, A. I., Bochkarev, S. V., \& Druzyakin, I. G. (2012). Management of the device by filing LNG in an energy installation. International science and technology journal Alternative Fuel Transport, 27(3), 30-32.

[6] Tsaplin, A. I. \& Bochkarev, S. V. (2013). Predicting technology of liquefied natural gas transportation by pipeline. Journal of Materials Science and Technology, 21(2), 114-125.

[7] Tic, V. \& Lovrec, D. (2012). Design of modern hydraulic tank using fluid flow simulation. International journal of simulation modelling, 11(2), 77-88. https://doi.org/10.2507/IJSIMM11(2)2.202

[8] Lovrec, D. \& Tic, V. (2011). Energy saving cooling-unit for plastic moulding machine. Strojniški vestnik, 57(2), 83-90. https://doi.org/10.5545/sv-jme.2010.082

[9] Tsaplin, A. I., Bochkarev, S. V., \& Seleznov, S. P. (2008). Development of a mathematical model of LNG drainage-free storage. International science and technology journal Alternative Fuel Transport, 2(2), 30-33.

[10] Tsaplin, A. I. \& Bochkarev, S. V. (2009). The method of thermal calculation of the carrier of liquefied natural gas. International science and technology journal Alternative Fuel Transport, 8(2), 70-73.

[11] Zagoruchenko, V. A. \& Zhuravlev, A. M. (1969). Thermophysical properties of gaseous and liquid methane. Gostandart of the USSR, 236-250.
[12] Tsaplin, A. I., Bochkarev, S. V., \& Druzyakin, I.G. (2013). Management of the feed LNG in fuel system of an engine. Journal of Materials Science and Technology, 35(5), 30-32.

[13] Pronin, E. N. (2008). Natural gas in engines-the fuel of the XXI century. International science and technology journal Alternative Fuel Transport, 2(2), 9-12.

[14] Morev, A. I. \& Erokhov. V. I. (1988). Operational and maintenance of gas cars. Transport, 184-190

[15] Petrovic, R. (2009). Mathematical modeling and experimental verification of operating parameters of vane pump with double effect. Strojniški vestnik, 55(1), 26-32. ISSN 0039-2480.

[16] Majdic, F. \& Pezdirnik, J. (2012). Oscilations of cylinder piston rod - comparison of amplitudes and frequencies fort hetransient phenomena in tap water- and oil-based PCHS. Journal of vibro engineering, 14(1), 352-362.

[17] Lovrec, D., Tasner, T., \& Tič, V. (2017). Dynamic behaviour of different hydraulic drive concepts - comparison and limits. International journal of simulation modelling, 16(3), 448457. https://doi.org/10.2507/IJSIMM16(3)7.389

[18] Petrovic, R. (2009). Mathematical modeling and experimental research of characteristic parameters of hydrodynamic processes in an axial piston pump. Strojniški vestnik, 55(4), 224-292.

[19] Banaszek, A. (2010). Flow control concept of submerged ballast pumps with hydraulic drive supplied from hydraulic central loading system on modern product and chemical tankers. $6^{\text {th }}$ FPNI-PhD Symposium International Conference on Hydraulics and Pneumatics, West Lafayette, Chicago, Purdue University USA

[20] Nikodijevic, M., Mijailovic, I., \& Raos, M. (2017). Maintenance of pressure equipment during its service life. Safety at Work 14. International Conference, Divcibare, 262-270.

[21] Nevrly, J. \& Brandejs, J. (2016). Methodology of hydraulic system development using experimental stand and computer modeling. MM Science Journal. https://doi.org/10.17973/MMSJ.2016_03_201604

[22] Obrovic, B., Savic, S., \& Petrovic, R. (2010). Ionized gas boundary layer on bodies of revolution in the presence of magnetic field. Tehnički vjesnik, 17(1), 35-42. https://hrcak.srce.hr/50604

[23] Petrovic, R., Pezdirnik, J., \& Todic, N. (2009). Optimization of oil-hydraulic cylinders of large measurements and strengths. Ventil - Journal for Fluid Power, Automation and Mechatronics, 15(1), 330-337.

\section{Contact information}

Milica NIKODIJEVIC, PhD Student

Faculty of Occupational Safety,

University of Nis,

Carnojevica 10a, 18000 Nis, Serbia

E-mail: milica.n.co@gmail.com

Radovan PETROVIC, Professor

(Corresponding author)

University "Union - Nikola Tesla" Belgrade,

Faculty for Strategic and Operational Management,

Staro sajmiste bb, 11000 Belgrade, Serbia

E-mail: radovan4700@yahoo.com

\section{Sergey V. BOCHKAREV, Professor}

Perm national research polytechnic university (PNRPU),

Microprocessor-based automation tools,

29 Komsomolsky prospekt, Perm, Russian Federation

E-mail: akf@cpl.pstu.ru 
Nenad TODIC, PhD Student

Faculty of Engineering,

University of Kragujevac,

Sestre Janjic 6, 34000 Kragujevac, Serbia

E-mail: ntodic@gmail.com

Ivica STANKOVIC, PhD Student

University "Union - Nikola Tesla" Belgrade,

Faculty for Strategic and Operational Management,

Staro sajmiste bb, 11000 Belgrade, Serbia

E-mail: ivica.stankovic@fpsp.edu.rs 